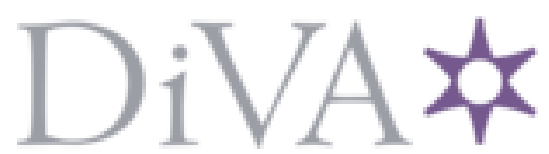

http://www.diva-portal.org

\title{
Postprint
}

This is the accepted version of a paper published in Archives of gerontology and geriatrics (Print). This paper has been peer-reviewed but does not include the final publisher proof-corrections or journal pagination.

Citation for the original published paper (version of record):

Hallgren, J., Fransson, E., Reynolds, C A., Finkel, D., Pedersen, N L. et al. (2018)

Cognitive trajectories in relation to hospitalization among older Swedish adults.

Archives of gerontology and geriatrics (Print), 74: 9-14

https://doi.org/10.1016/j.archger.2017.09.002

Access to the published version may require subscription.

N.B. When citing this work, cite the original published paper.

Permanent link to this version:

http://urn.kb.se/resolve?urn=urn:nbn:se:hj:diva-29963 


\section{Cognitive trajectories in relation to hospitalization among older Swedish adults}

\section{Authors:}

Jenny Hallgren ${ }^{* 1} \mathrm{PhD}$; Eleonor I. Fransson ${ }^{2,3} \mathrm{PhD}$; Chandra A. Reynolds PhD ${ }^{4}$; Deborah Finkel PhD ${ }^{5}$; Nancy L. Pedersen $\mathrm{PhD}^{6}$; Anna K. Dahl Aslan PhD ${ }^{1,6}$

\section{Affiliations:}

${ }^{1}$ Institute of Gerontology, School of Health and Welfare, Jönköping University, Jönköping, Sweden

${ }^{2}$ Department of Natural Science and Biomedicine, School of Health and Welfare, Jönköping University, Jönköping, Sweden

${ }^{3}$ Institute of Environmental Medicine, Karolinska Institutet, Stockholm, Sweden

${ }^{4}$ Department of Psychology, University of California, Riverside, USA

${ }^{5}$ School of Social Sciences, Indiana University Southeast, New

Albany, USA

${ }^{6}$ Department of Medical Epidemiology and Biostatistics, Karolinska Institutet, Stockholm, Sweden

\section{*Corresponding author:}

Jenny Hallgren, Institute of Gerontology, School of Health and Welfare, Jönköping University, 55111 Jönköping, Sweden

Phone: +46 702476768; E-mail: jenny.hallgren@ju.se

Running head: Cognitive trajectories and hospitalization 


\begin{abstract}
Introduction: Research indicate that cognitive impairment might be related to hospitalization, but little is known about these effects over time.

Objective: To assess cognitive change before and after hospitalization among older adults in a population-based longitudinal study with up to 25 years of follow-up.

Method: A longitudinal study on 828 community living men and women aged 50-86 from the Swedish Adoption/Twin Study of Ageing (SATSA) were linked to The Swedish National Inpatient Register. Up to 8 assessments of cognitive performance (general cognitive ability, verbal, spatial/fluid, memory, and processing speed) from 1986 to 2010 were available. Latent growth curve modelling was used to assess the association between cognitive performance and hospitalization including spline models to analyse cognitive trajectories pre- and posthospitalization.
\end{abstract}

Results: A total of 735 persons (89\%) had at least one hospital admission during the follow-up. Mean age at first hospitalization was 70.2 ( \pm 9.3) years. Persons who were hospitalized exhibited a lower mean level of cognitive performance in general ability, processing speed and spatial/fluid ability compared with those who were not hospitalized. The two-slope models revealed steeper cognitive decline before hospitalization than after among those with at least one hospitalization event, as compared to non-hospitalized persons who showed steeper cognitive decline after the centering age of 70 years.

Conclusions: Persons being hospitalized in late life have lower cognitive performance across all assessed domains. The results indicate that the main decline occurs before the hospitalization, and not after. This might indicate that when you get treatment you also benefit cognitively.

Keywords: Hospitalization; cognition; latent growth curve modelling; longitudinal study; old age 


\section{Introduction}

Older people admitted to the hospital are at risk of experiencing adverse effects following their hospitalization, such as functional decline and increased risk of nosocomial infections (Klevens et al., 2007). Research has suggested that hospitalization per se is associated with not only functional and medical adverse outcomes but also the development of cognitive decline (Ehlenbach et al., 2010; Mathews, Arnold, \& Epperson, 2014; Pandharipande et al., 2013; R. S. Wilson et al., 2012) and an increased risk of dementia (Ehlenbach et al., 2010). Conditions that are common among hospitalized persons, e.g. functional decline (Boyd, Xue, Simpson, Guralnik, \& Fried, 2005; Volpato et al., 2007) and frailty (Buchman, Boyle, Wilson, Tang, \& Bennett, 2007), as well medical conditions common in the general population such as diabetes mellitus and chronic pulmonary disease (Arvanitakis, Wilson, Bienias, Evans, \& Bennett, 2004; Hung, Wisnivesky, Siu, \& Ross, 2009) are associated with cognitive decline. Loss of cognitive ability may increase individuals' likelihood of experiencing comorbid medical conditions because cognitive impairments are associated with a lower level of health literacy (Baker, Wolf, Feinglass, \& Thompson, 2008) and health-related behaviours such as medication adherence (Insel, Morrow, Brewer, \& Figueredo, 2006). However, whether the effect of hospitalization simply is a marker of cognitive decline or accelerates the progression of cognitive decline or both, remains unknown.

Previous studies have shown that cognitive impairment might be related to hospitalization immediately at discharge and several months post-discharge (Chen, Chiu, Chen, Cheng, \& Huang, 2011; Mathews et al., 2014; Volpato et al., 2007). Whether these effects are transient, persistent, or even accelerate over time is unknown. A study conducted by Wilson et al (2012) suggested that persons who had experienced hospitalization had a greater likelihood of displaying general cognitive decline than those who had not been hospitalized. Another study 
found greater cognitive decline in persons with acute care- and critical illness hospitalizations (Ehlenbach et al., 2010) compared to persons not hospitalized. Furthermore, few studies have analysed the association between hospitalization and different cognitive domains (Mathews et al., 2014). Those that have, observed declines in global cognition, executive function, memory, and processing speed post-hospitalization, but these studies did not employ objective prehospital cognitive measurements, (Pandharipande et al., 2013; Rothenhäusler, Ehrentraut, Stoll, Schelling, \& Kapfhammer, 2001) or they used data from a restricted geographical area within one city (R. S. Wilson et al., 2012).

Cognitive impairment after hospitalization may be a growing health problem given the demographic trend of an increased proportion of older people, who are at an increased risk of diseases and disabilities and potentially greater health care use. An understanding of the change in older persons' different cognitive domains before and after hospitalization can improve care and direct further investigations of these potential associations. Hence, this population-based longitudinal study of cognitive functions with up to 25 years of follow-up aimed to examine changes in older adults’ cognition before and after hospitalization.

\section{Material and methods}

\subsection{Sample}

Data from the population-based longitudinal Swedish Adoption/Twin Study of Ageing (SATSA) were used. The SATSA participants were drawn from the Swedish Twin Registries (STR) and included same-sex twin pairs either reared together or reared apart. The selection criteria has been described in detail elsewhere (Finkel \& Pedersen, 2004). In brief, in 1984, the first SATSA Questionnaire (Q1) was administered to study the aetiology of individual differences in ageing. Pairs of twins aged 50 years and above that participated in Q1 were invited to complete In Person Testing (IPT), which included biomedical and cognitive 
examinations, in 1986. On average, IPT was conducted every third year. A total of 859 persons participated in cognitive testing in at least one SATSA wave. Twins with complete data on the four included cognitive domains, i.e. verbal, spatial/fluid, memory, and processing speed, were included in this study $(\mathrm{n}=828)$. This selection procedure was followed to assess the same $\mathrm{N}$ and individuals across all analyses.

\subsection{Measures}

\subsubsection{Cognitive abilities}

Four cognitive domains, verbal, spatial/fluid, memory and processing speed abilities, were assessed in the SATSA cognitive test battery (Nesselroade, Pedersen, McClearn, Plomin, \& Bergeman, 1988; Pedersen, Plomin, Nesselroade, \& McClearn, 1992). The study assessed verbal abilities using the Information Subtest (from the Wechsler Adult Intelligence ScaleRevised [WAIS-R] (Wechsler, 1981), Synonyms, and Analogies, and memory using Digit Span (WAIS-R) and Thurstone’s Picture Memory Task. Spatial/fluid abilities were assessed by Figure Logic, Block design (WAIS-R), and Card Rotation. Processing speed was assessed using Symbol Digit (an inverted version of the Symbol Digit Substitution task (Smith, 1982), and Figure Identification.

Principal component analysis was used to create component scores for each of the four domains, verbal, spatial/fluid, memory and processing speed abilities. In addition, a global cognitive composite score was created by combining the cognitive scores of all subtests on each testing occasion (Finkel \& Pedersen, 2004). Finally, for ease in interpretation, the cognitive component scores were transformed into T scores, with a mean of 50 and a standard deviation of 10 , relative to scores at IPT1.

\subsubsection{Dementia}


Participants with low scores on the MMSE (below 25) or who evidenced a 10 percent decline in MMSE scores from the previous IPT were evaluated for dementia during consensus conferences. Likewise, we evaluated the following individuals for dementia: all those who scored low on the Block Design and Synonyms tests, those whose medical records included notes about cognitive problems, those suspected of having dementia by the research nurses, and/or those who had cognitive problems according to a proxy (Gatz \& Pedersen, 2013). A consensus conference taking all available information into account from medical records, cognitive test scores and changes in cognitive test scores including MMSE scores, and nurses evaluations was conducted to define dementia cases (Bokenberger, Pedersen, Gatz, \& Dahl, 2014; Gatz et al., 1997). Dementia was diagnosed according to the Diagnostic and Statistical Manual of Mental Disorders (DSMM) dementia criteria at the time of diagnosis.

\subsubsection{Hospitalization}

The study sample was linked to The Swedish National Patient Register (NPR) (National Board of Health and Welfare), which contains information on the participants' hospital admissions during their participation in SATSA, up to 31 December 2012. The participants' first hospitalization for any reason after their entry in SATSA was included. Twins with hospital admissions before their entry in SATSA $(n=35)$ but not during the study follow-up were regarded as not being admitted to the hospital. Participants’ mean number of admissions during their participation in SATSA (up to 25 years) was 5.3.( \pm 7.0$)$

\subsubsection{Covariates}

We included covariates that are known to be related to cognitive functions: age, sex, and education (dichotomised as upper secondary or university education (1) and compulsory or vocational education (0)). Covariates were drawn from the IPT prior to participants' first 
hospitalization. For participants without hospitalizations, the covariates were drawn from the baseline IPT. We controlled for number of illnesses (based on a sum of 13 domains of selfreported illnesses) (Harris, Pedersen, Stacey, McClearn, \& Nesselroade, 1992) and depressive symptoms, as measured by the Center for Epidemiologic Studies Depression Scale (CES-D) (Gatz, Johansson, Pedersen, Berg, \& Reynolds, 1993). We also included self-rated health, which was measured on a scale comprising individuals' current general health, current health versus health 5 years ago, own health compared with others' health and limitations in activities due to health. The total number of hospitalizations was extracted from the NPR. We included all of the participants' hospitalizations to the end of the study or death. We also included numbers of years from the first hospitalization to the subsequent IPT in SATSA (for the hospitalized participants).

\subsection{Statistical analyses}

Age-based latent growth curve modelling was used to measure change in cognitive performance over time and to explore the potential association between hospitalization and cognitive performance across different domains over time. The models included fixed effects and random effects (both within and between pairs to adjust for dependency) using age centred at first hospitalization for those who were hospitalized. For those who had not been hospitalized $(n=93)$, age was centred at the mean age of hospitalization (70.2 years). For twins who had not reached the age of $70(n=48)$ and were not hospitalized, age was centred at their age at their last IPT wave (63.7 \pm 4.5 years).

To explore the cognitive trajectories and its relation to hospitalization, spline models incorporating two linear slopes modeling trajectories pre-and post- hospitalization for the hospitalized participants, and pre- and post the age of 70 (mean age for the first hospitalization) for the non-hospitalized participants were conducted. In the first model (Model 1) the total 
sample was included and adjusted for age, sex and education. In Model 2, separate analyses were conducted for the hospitalized and non-hospitalized participants, adjusted for age, sex and education. In the next step (Model 3), again, separate analyses were conducted for the hospitalized and non hospitalized participants adjusted for age, sex and education, and number of illnesses, self-rated health, depression, number of admissions and number of years from the first hospitalization to the next IPT in SATSA (for the hospitalized participants), were also included as covariates. In the final step (Model 4), dementia was additionally included as a covariate. In all models, we controlled relatedness within twin pairs. All analyses were run using PROC Mixed in SAS 9.2 (SAS, 2009).

\section{Results}

Of the 828 twins, 735 (89\%) had at least one hospital admission during their participation in SATSA. The most common primary diagnoses, for all admissions, were cardiovascular disease (24\%) and tumors (10\%) (Supplementary). At baseline, hospitalized participants had a mean age of $63.4( \pm 8.3)$ years and non-hospitalized participants’ mean age was $60.7( \pm 7.3)$ years. Those who were hospitalized were in SATSA shorter time before age 70/hospitalization than those who were not hospitalized. Hospitalized participants were more likely to have lower levels of education, more illnesses, lower self-rated health, and more depressive symptoms (Table 1). 
Table 1.

Baseline characteristics. $^{\text {a }}$

\begin{tabular}{|c|c|c|c|c|}
\hline \multirow[b]{4}{*}{ Variables } & & Participants with no & Participants with & \multirow{4}{*}{$\begin{array}{l}\text { p-value for t-test or } \\
\text { Chi-square }\end{array}$} \\
\hline & All & hospitalization & hospitalization & \\
\hline & $\mathrm{N}=828$ & $\mathrm{n}=93$ & $n=735$ & \\
\hline & Mean (SD) & Mean (SD) & Mean (SD) & \\
\hline Age at baseline & $63.1 \pm 8.3$ & $60.7 \pm 7.3$ & $63.4 \pm 8.3$ & 0.004 \\
\hline Sex, n (\%) & & & & 0.523 \\
\hline Male & 337 (40.7\%) & 35 (37.6\%) & 302 (41.1\%) & \\
\hline Female & 491 (59.3\%) & $58(62.4 \%)$ & 433 (58.9\%) & \\
\hline \multicolumn{5}{|l|}{ Education } \\
\hline Elementary & 697 (86.9\%) & $66(78.6 \%)$ & $631(87.9 \%)$ & 0.017 \\
\hline Higher education & $105(13.1 \%)$ & $18(21.4 \%)$ & $87(12.1 \%)$ & \\
\hline Number of illnesses $(0-11)$ & $2.6^{c}(1.9)$ & $1.9(1.4)$ & $2.7(2.0)$ & 0.001 \\
\hline Self-rated health $(-9.1-5.2)$ & $0.2(2.8)$ & $1.4(1.7)$ & $0.1(2.9)$ & $<.001$ \\
\hline Dementia & $94(11.4 \%)$ & $2(2.2 \%)$ & $92(12.5 \%)$ & 0.003 \\
\hline Depression $(C E S D)^{b}(0$ - 50) & $10.6(7.8)$ & $8.2(6.5)$ & 10.9 (7.9) & 0.003 \\
\hline Number of admissions & & & $8.5^{\mathrm{d}}(7.0)$ & \\
\hline \multicolumn{5}{|l|}{ Number of years in SATSA } \\
\hline before hospitalization/age of 70 & $7.1^{\mathrm{e}}(6.4)$ & $12.5(6.6)$ & $6.4(6.0)$ & $<.001$ \\
\hline after hospitalization/age of 70 & $6.8^{f}(6.6)$ & $3.9(5.5)$ & $6.8(6.7)$ & $<.001$ \\
\hline
\end{tabular}

${ }^{a}$ At the IPT prior to first hospitalization or the participants' first IPT in SATSA.

${ }^{\mathrm{b} C e n t e r}$ for Epidemiologic Studies Depression Scale.

'Median 2.0, ${ }^{\mathrm{d}}$ Median 6.0, ${ }^{\mathrm{e}}$ Median 5.7, ${ }^{\mathrm{f}}$ Median 4.4

\subsection{Hospitalization and Cognitive Functioning}

In Model 1, including both hospitalized and non hospitalized participants controlling for age, sex and education, significant differences in the intercept were observed, suggesting that hospitalized participants displayed lower cognitive test scores in general ability, processing speed and spatial/fluid ability performance at the time of the first hospitalization event 
compared to non-hospitalized particpants. In Model 2, for the hospitalized participants significant pre-hospitalization decline in cognition was seen in verbal ability, and a tendency was seen in general ability $(\mathrm{p}=0.059)$. Statistically significant increase in cognition posthospitalization was seen in memory ability and a tendency was seen in spatial/flud ability $(p=0.056)$. For the non hospitalized participants, pre 70 years' significant cognitive decline was seen in processing speed ability, and significant cognitive decline post 70 years' was seen in all cognitive domains.

In Model 3, which added number of illnesses, depression, self-rated health, number of admissions after the first hospitalization and number of years from the first hospitalization to the next IPT in SATSA, significant pre-hospitalization decline was observed in general ability and verbal abililty among the hospitalized participants. Among the non hospitalized participants, a reverse pattern was observed, and statistically significant post 70 years' decline was seen in all cognitive domains. In Model 4, dementia was added as a covariate. The same patterns observed in the former models were found, and this model improved the -2log likelihood (Table 2). 
Table 2

Change in cognitive performance pre-and post hospitalization or 70 years of age for non-hospitalized participants using latent growth curve modelling.

\begin{tabular}{|c|c|c|c|c|c|c|c|c|c|c|c|c|c|c|c|}
\hline & \multicolumn{3}{|c|}{ General ability } & \multicolumn{3}{|c|}{ Verbal } & \multicolumn{3}{|c|}{ Spatial/fluid ability } & \multicolumn{3}{|c|}{ Memory } & \multicolumn{3}{|c|}{ Processing Speed } \\
\hline Model 1 & Est. & SE & $p$ & Est. & SE & $p$ & Est. & SE & $p$ & Est. & SE & $p$ & Est. & $\begin{array}{l}\mathrm{SE} \\
\end{array}$ & $p$ \\
\hline Intercept & 47.26 & 0.70 & $<.0001$ & 47.21 & 0.78 & $<.0001$ & 46.90 & 0.66 & $<.0001$ & 48.68 & 0.64 & $<.0001$ & 48.23 & 0.58 & $<.0001$ \\
\hline Non hospitalized & 3.13 & 1.22 & 0.0106 & 0.80 & 1.35 & 0.5555 & 3.53 & 1.25 & 0.005 & 0.045 & 1.27 & 0.726 & 6.21 & 1.22 & $<.0001$ \\
\hline Pre hospitalization & -0.21 & 0.07 & 0.0052 & -0.24 & 0.09 & 0.0090 & -0.15 & 0.07 & 0.043 & -0.13 & 0.07 & 0.064 & -0.13 & 0.06 & 0.0379 \\
\hline $\begin{array}{l}\text { Post hospitalization } \\
\text {-2log likelihood }\end{array}$ & $\begin{array}{l}0.10 \\
17573.3\end{array}$ & 0.06 & 0.1072 & $\begin{array}{l}0.14 \\
18508.7\end{array}$ & 0.07 & 0.0300 & $\begin{array}{l}0.05 \\
19000.0\end{array}$ & 0.06 & 0.718 & $\begin{array}{l}0.18 \\
21383.9\end{array}$ & 0.06 & 0.002 & $\begin{array}{l}-0.04 \\
21476.5\end{array}$ & 0.006 & 0.4616 \\
\hline $\begin{array}{l}\text { Model } 2 \\
\text { Hospitalized }\end{array}$ & & & & & & & & & & & & & & & \\
\hline Intercept & 47.13 & 0.75 & $<.0001$ & 47.25 & 0.84 & $<.0001$ & 46.64 & 0.69 & $<.0001$ & 48.71 & 0.69 & $<.0001$ & 48.02 & 0.61 & $<.0001$ \\
\hline Pre hospitalization & -0.16 & 0.08 & 0.0590 & -0.21 & 0.10 & 0.0387 & -0.09 & 0.08 & 0.2720 & -0.11 & 0.08 & 0.1791 & -0.11 & 0.06 & 0.087 \\
\hline $\begin{array}{l}\text { Post hospitalization } \\
\text {-2log likelihood } \\
\text { Non hospitalized }\end{array}$ & $\begin{array}{l}0.14 \\
15499.4\end{array}$ & 0.08 & 0.0908 & $\begin{array}{l}0.10 \\
16358.2\end{array}$ & 0.09 & 0.3080 & $\begin{array}{l}0.15 \\
16715.5\end{array}$ & 0.08 & 0.0560 & $\begin{array}{l}0.20 \\
18944.7\end{array}$ & 0.08 & 0.0192 & $\begin{array}{l}0.03 \\
18974.5\end{array}$ & 0.07 & 0.6605 \\
\hline Intercept & 54.93 & 1.31 & $<.0001$ & 54.66 & 1.23 & $<.0001$ & 52.57 & 1.49 & $<.0001$ & 54.10 & 1.24 & $<.0001$ & 54.85 & 1.32 & $<.0001$ \\
\hline Pre 70 years & -0.06 & 0.05 & 0.236 & 0.07 & 0.05 & 0.1465 & -0.12 & 0.07 & 0.0749 & 0.05 & 0.07 & 0.4690 & -0.26 & 0.07 & 0.0001 \\
\hline $\begin{array}{l}\text { Post } 70 \text { years } \\
\text {-2log likelihood }\end{array}$ & $\begin{array}{l}-0.51 \\
1988.0 \\
\end{array}$ & 0.07 & $<.0001$ & $\begin{array}{l}-0.25 \\
2078.7 \\
\end{array}$ & 0.06 & 0.0003 & $\begin{array}{l}-0.34 \\
2242.8 \\
\end{array}$ & 0.11 & 0.0032 & $\begin{array}{l}-0.50 \\
2401.0 \\
\end{array}$ & 0.12 & 0.0001 & $\begin{array}{l}-0.63 \\
2399.5 \\
\end{array}$ & 0.09 & $<.0001$ \\
\hline $\begin{array}{l}\text { Model } 3 \\
\text { Hospitalized } \\
\end{array}$ & & & & & & & & & & & & & & & \\
\hline Intercept & 48.66 & 0.95 & $<.0001$ & 50.13 & 1.06 & $<.0001$ & 47.19 & 0.91 & $<.0001$ & 47.40 & 0.87 & $<.0001$ & 46.62 & 0.80 & $<.0001$ \\
\hline Pre hospitalization & -0.20 & 0.09 & 0.0350 & -0.31 & 0.11 & 0.0049 & -0.08 & 0.09 & 0.4241 & -0.13 & 0.09 & 0.1433 & -0.11 & 0.07 & 0.1249 \\
\hline $\begin{array}{l}\text { Post hospitalization } \\
\text {-2log likelihood } \\
\text { Non hospitalized }\end{array}$ & $\begin{array}{l}0.03 \\
11360.2\end{array}$ & 0.14 & 0.8291 & $\begin{array}{l}-0.09 \\
11925.1\end{array}$ & 0.15 & 0.5337 & $\begin{array}{l}0.12 \\
12354.2\end{array}$ & 0.13 & 0.0986 & $\begin{array}{l}0.19 \\
13931.5\end{array}$ & 0.14 & 0.1842 & $\begin{array}{l}-0.09 \\
14202.7\end{array}$ & 0.12 & 0.4439 \\
\hline Intercept & 49.21 & 1.97 & $<.0001$ & 55.44 & 1.75 & $<.0001$ & 47.67 & 2.29 & $<.0001$ & 50.79 & 1.85 & $<.0001$ & 46.53 & 1.86 & $<.0001$ \\
\hline Pre 70 years & -0.04 & 0.05 & 0.4870 & 0.09 & 0.05 & 0.0956 & -0.09 & 0.06 & 0.1740 & 0.06 & 0.07 & 0.4183 & -0.27 & 0.07 & 0.0001 \\
\hline $\begin{array}{l}\text { Post } 70 \text { years } \\
\text {-2log likelihood }\end{array}$ & $\begin{array}{l}-0.53 \\
1805.9\end{array}$ & 0.07 & $<.0001$ & $\begin{array}{l}-0.29 \\
2028.6\end{array}$ & 0.07 & 0.0002 & $\begin{array}{l}-0.35 \\
2022.7\end{array}$ & 0.11 & 0.0028 & $\begin{array}{l}-0.53 \\
2191.7\end{array}$ & 0.13 & 0.0002 & $\begin{array}{l}-0.59 \\
2167.8\end{array}$ & 0.09 & $<.0001$ \\
\hline $\begin{array}{l}\text { Model } 4 \\
\text { Hospitalized }\end{array}$ & & & & & & & & & & & & & & & \\
\hline Intercept & 49.09 & 0.96 & $<.0001$ & 50.46 & 1.06 & $<.0001$ & 50.07 & 0.92 & $<.0001$ & 48.03 & 0.86 & $<.0001$ & 46.98 & 0.81 & $<.0001$ \\
\hline Pre hospitalization & -0.18 & 0.09 & 0.0441 & -0.29 & 0.11 & 0.0067 & -0.07 & 0.09 & 0.4882 & -0.12 & 0.09 & 0.2002 & -0.11 & 0.07 & 0.1249 \\
\hline
\end{tabular}




\begin{tabular}{|c|c|c|c|c|c|c|c|c|c|c|c|c|c|c|c|}
\hline $\begin{array}{l}\text { Post hospitalization } \\
\text {-2log likelihood } \\
\text { Non hospitalized }\end{array}$ & $\begin{array}{l}0.04 \\
11346 .\end{array}$ & 0.14 & 0.7536 & $\begin{array}{l}-0.09 \\
11919.1\end{array}$ & 0.15 & 0.5593 & $\begin{array}{l}0.14 \\
12343.8\end{array}$ & 0.13 & 0.3142 & $\begin{array}{l}0.22 \\
13903.6\end{array}$ & 0.13 & 0.1127 & $\begin{array}{l}-0.09 \\
14193.5\end{array}$ & 0.12 & 0.4738 \\
\hline Intercept & 50.37 & 1.96 & $<.0001$ & 54.09 & 1.97 & $<.0001$ & 50.30 & 2.18 & $<.0001$ & 52.67 & 1.95 & $<.0001$ & 48.19 & 1.90 & $<.0001$ \\
\hline Pre 70 years & -0.04 & 0.05 & 0.5358 & 0.08 & 0.05 & 0.0973 & -0.09 & 0.07 & 0.1829 & 0.07 & 0.07 & 0.3689 & -0.27 & 0.07 & 0.0002 \\
\hline $\begin{array}{l}\text { Post } 70 \text { years } \\
\text {-2log likelihood }\end{array}$ & $\begin{array}{l}-0.51 \\
1735.2\end{array}$ & 0.07 & $<.0001$ & $\begin{array}{l}-0.29 \\
2004.3\end{array}$ & 0.07 & 0.0002 & $\begin{array}{l}-0.35 \\
2008.6\end{array}$ & 0.10 & 0.0023 & $\begin{array}{l}-0.52 \\
2182.1\end{array}$ & 0.13 & 0.0003 & $\begin{array}{l}-0.59 \\
2159.4\end{array}$ & 0.13 & $<.0001$ \\
\hline
\end{tabular}

Model 1 and 2 Adjusted for age, sex and education.

Model 3 Adjusted age, sex, education, number of illnesses, self-rated health, depression, number of admissions (for the hospitalized participants), numbers of years between

the first hospitalization and subsequent in person testing.

Model 4 Adjusted for age, sex, education, number of illnesses, self-rated health, depression, number of admissions (for the hospitalized participants), numbers of years

between the first hospitalization and subsequent in person testing, and dementia

Age was centred at first hospitalization for those hospitalized. For those not hospitalized, age was centred at the mean age of hospitalization (70.2 years). 
In general, the hospitalized participants had a steeper slope of cognitive decline before their hospitalization event, followed by a flatter slope or an increase after their hospitalization event. For the non-hospitalized participants, whose centered age was set to 70 years of age in the twoslope models, the slope of cognitive change was steeper after the age of 70 in all domains (Figure 1).

\section{Insert Figure 1 about here}

\section{Discussion}

In this study, we adopted a longitudinal design with objective cognitive measures in different domains and followed a cohort of older individuals for up to 25 years to evaluate cognitive change before and after hospitalization. The results revealed that there were differences in the mean level of cognitive abilities at age 70 across several domains between hospitalized and non-hospitalized participants. Further, when analysing the trajectories of cognitive functioning using two-slope models, the steepest decline was observed in the period preceding the hospitalization event for the hospitalized persons, while persons without hospitalizations experienced their steeper decline in cognition after the age of 70, which is typical results for LGCM in cognitive change in normative samples. These patterns remained even after controlling for dementia.

In line with our finding, a prior study of cognitive development post-hospitalization during a shorter follow-up time (six months) found decline was followed by improvement (Chen et al., 2011). Further, Wilson et al (2013), discovered that both lower level of cognitive functioning and more rapid cognitive decline were related to increased rate of hospitalization and suggested that cognitive dysfunction may be an early marker of a subsequent condition that will require hospitalization. On the other hand, other similar studies did not find similar associations 
(Chodosh et al., 2004; Ehlenbach et al., 2010). In general, cognitive aging is not represented by a single homogeneous trajectory, rather it is a heterogeneous process. Han et al (2016) identified five different cognitive trajectories among community-living older persons i.e. no decline, minimal, moderate, progressive and rapid decline, where the latter two patterns were also related to the highest burden of disability. Interestingly, they did not find that burden of hospitalization was uniformly associated with cognitive decline, and suggested future studies including domain-specific cognitive measures and reasons for hospitalization.

Cognitive impairment associated with hospitalization might depend on the reason for hospitalization (Hopkins \& Jackson, 2006; Pandharipande et al., 2013). However, in the ACT study (Ehlenbach et al., 2010), no difference in cognitive decline was found between persons who were hospitalized due to a critical or a non-critical illness. In the current study, only $2.5 \%$ of the hospitalizations were due to a critical illness according to Ehlenbach's definition, and the data were insufficient to support separate analyses for this group. However, since our analyses suggest that the decline in cognition may start already a few years prior to hospitalization, the hospitalization itself may not be the essential factor, but rather the medical condition preceding the hospitalization event or other factors such as genetic differences, or associated treatment as seen in prior research (Roach et al., 1996).

We found that persons who subsequently experienced hospitalization displayed a more rapid cognitive decline pre-hospitalization, especially in verbal ability and general ability. The performance in these domains however seemed to recover or at least not decline as fast after the hospitalization indicating that the hospital treatment might have cognitive benefits. The noticed pattern might have to do with the origin of these abilities. Verbal abilities are to a higher extent learned knowledge and correlated to educational achievements than spatial/fluid ability and processing speed that to a higher extent have a biological base. Normative cognitive aging in fluid abilities is to a less exent influenced by environmental factors than crystalized abilities. 
This study extends this knowledge by showing that hospitalization does not substantially change the expected pattern of cognitive decline in fluid abilities.

Major strengths of this study include the objective cognitive measurements of different cognitive domains before and after hospitalization, the long duration of follow-up and the use of national hospitalization records with complete coverage. Another strength is the populationbased prospective design including both community-living older persons and older persons living in nursing homes. A further strength is the ability to control for dementia diagnosis. SATSA participants are extensively screened for dementia and evaluated at a consensus conference. The longitudinal design of the study, use of repeated measures of cognitive functions and access to medical records minimise the risk that persons with dementia were undiagnosed. However, this study also has limitations. The long follow-up time is both a strength and a weakness. Intervening events occurring between the assessments were not captured and may influence the outcome. Although the follow-up time in this study is more than 20 years for some of the participants, the average time interval between the IPT waves is three years, limiting our possibility to capture short-term changes in cognition around the hospital event. Trajectories occurring directly after the event or factors beyond hospital admissions that affect the development of cognitive decline may therefore not have been captured. Another limitation is that we did not control for illnesses affecting the participants during the follow-up period. We included individuals' health status at the IPT directly before hospitalization, but other illnesses that did not demand hospitalization might have occurred during the follow-up period, and these illnesses may have affected participants' cognitive change. 


\section{Conclusions}

The present results contradict an association between hospitalization and subsequent steeper cognitive decline. Rather, the results indicate that persons with cognitive impairment are particularly at risk of being hospitalized, while their decline in cognition is attenuated after their hospitalization. It is beyond the scope of this study to determine factors affecting the cognitive change pre hospitalization, however, future studies are warranted.

\section{Acknowledgements}

This work was supported by the Swedish Research Council for Health, Working Life and Welfare [2013-2292] and the Swedish Research Council [521-2013-8689].The Swedish Adoption/Twin Study of Aging was supported by grants from the National Institutes of Health [AG 04563, AG10175], the MacArthur Foundation Research Network on Successful Aging, the Swedish Council for Working Life and Social Research [97:0147:1B, FAS 2009-0795], and the Swedish Research Council [825-2007-7460, 825-2009-6141].

\section{Conflict of interest}

The authors declare no financial or personal conflict of interest. 


\section{References}

Arvanitakis, Z., Wilson, R. S., Bienias, J. L., Evans, D. A., \& Bennett, D. A. (2004). Diabetes mellitus and risk of Alzheimer disease and decline in cognitive function. Arch Neurol, 61(5), 661-666.

Baker, D. W., Wolf, M. S., Feinglass, J., \& Thompson, J. A. (2008). Health literacy, cognitive abilities, and mortality among elderly persons. J Gen Intern Med, 23(6), 723-726.

Bokenberger, K., Pedersen, N. L., Gatz, M., \& Dahl, A. K. (2014). The Type A behavior pattern and cardiovascular disease as predictors of dementia. Health Psychology, 33(12), 1593. doi:10.1037/hea0000028

Boyd, C. M., Xue, Q.-L., Simpson, C. F., Guralnik, J. M., \& Fried, L. P. (2005). Frailty, hospitalization, and progression of disability in a cohort of disabled older women. Am J Med, 118(11), 1225-1231.

Buchman, A. S., Boyle, P. A., Wilson, R. S., Tang, Y., \& Bennett, D. A. (2007). Frailty is associated with incident Alzheimer’s disease and cognitive decline in the elderly. Psychosom Med, 69(5), 483-489.

Chen, C. C.-H., Chiu, M.-J., Chen, S.-P., Cheng, C.-M., \& Huang, G.-H. (2011). Patterns of cognitive change in elderly patients during and 6 months after hospitalisation: a prospective cohort study. International Journal of Nursing Studies, 48(3), 338-346.

Chodosh, J., Seeman, T. E., Keeler, E., Sewall, A., Hirsch, S. H., Guralnik, J. M., \& Reuben, D. B. (2004). Cognitive Decline in High-Functioning Older Persons Is Associated with an Increased Risk of Hospitalization. Journal of the American Geriatrics Society, 52(9), 1456-1462.

Ehlenbach, W. J., Hough, C. L., Crane, P. K., Haneuse, S. J., Carson, S. S., Curtis, J. R., \& Larson, E. B. (2010). Association between acute care and critical illness 
hospitalization and cognitive function in older adults. JAMA, 303(8), 763-770. doi:10.1001/jama.2010.167

Finkel , D., \& Pedersen, N. L. (2004). Processing speed and longitudinal trajectories of change for cognitive abilities: the Swedish adoption/twin study of aging. Aging Neuropsychol C, 11(2-3), 325-345.

Gatz, M., Johansson, B., Pedersen, N., Berg, S., \& Reynolds, C. (1993). A cross-national selfreport measure of depressive symptomatology. int Psychogeriatr, 5(02), 147-156.

Gatz, M., \& Pedersen, N. L. (2013). Study of dementia in Swedish twins. Twin Research and Human Genetics, 16(01), 313-316.

Gatz, M., Pedersen, N. L., Berg, S., Johansson, B., Johansson, K., Mortimer, J. A., . . . Ahlbom, A. (1997). Heritability for Alzheimer's disease: the study of dementia in Swedish twins. The Journals of Gerontology Series A: Biological Sciences and Medical Sciences, 52(2), M117-M125. doi:10.1093/gerona/52A.2.M117

Han, L., Gill, T. M., Jones, B. L., \& Allore, H. G. (2016). Cognitive aging trajectories and burdens of disability, hospitalization and nursing home admission among communityliving older persons. The Journals of Gerontology Series A: Biological Sciences and Medical Sciences, 71(6), 766-771.

Harris, J. R., Pedersen, N. L., Stacey, C., McClearn, G., \& Nesselroade, J. R. (1992). Age differences in the etiology of the relationship between life satisfaction and self-rated health. Journal of Aging and Health, 4(3), 349-368.

doi:10.1177/089826439200400302

Hopkins, R. O., \& Jackson, J. C. (2006). Long-term neurocognitive function after critical illness. Chest, 130(3), 869-878. 
Hung, W. W., Wisnivesky, J. P., Siu, A. L., \& Ross, J. S. (2009). Cognitive decline among patients with chronic obstructive pulmonary disease. Am J Respir Crit Care Med, 180(2), 134-137.

Insel, K., Morrow, D., Brewer, B., \& Figueredo, A. (2006). Executive function, working memory, and medication adherence among older adults. J Gerontol B Psychol Sci Soc Sci, 61(2), P102-P107.

Klevens, R. M., Edwards, J. R., Richards, C. L., Horan, T. C., Gaynes, R. P., Pollock, D. A., \& Cardo, D. M. (2007). Estimating health care-associated infections and deaths in US hospitals, 2002. Public Health Rep, 122(2), 160.

Mathews, S. B., Arnold, S. E., \& Epperson, C. N. (2014). Hospitalization and cognitive decline: can the nature of the relationship be deciphered? Am J Geriatr Psychiatry, 22(5), 465-480.

National Board of Health and Welfare. National Inpatient Register [Patientregistret]. from http://socialstyrelsen.se/register/halsodataregister/patientregistret.

Nesselroade, J. R., Pedersen, N. L., McClearn, G. E., Plomin, R., \& Bergeman, C. (1988). Factorial and criterion validities of telephone-assessed cognitive ability measures age and gender comparisons in adult twins. Res Aging, 10(2), 220-234.

Pandharipande, P. P., Girard, T. D., Jackson, J. C., Morandi, A., Thompson, J. L., Pun, B. T., . . Ely, E. W. (2013). Long-term cognitive impairment after critical illness. New England Journal of Medicine, 369(14), 1306-1316 1311p. doi:10.1056/NEJMoa1301372

Pedersen, N. L., Plomin, R., Nesselroade, J. R., \& McClearn, G. E. (1992). A quantitative genetic analysis of cognitive abilities during the second half of the life span. Psychological Science, 3(6), 346-353. 
Roach, G. W., Kanchuger, M., Mangano, C. M., Newman, M., Nussmeier, N., Wolman, R., . . . Ley, C. (1996). Adverse cerebral outcomes after coronary bypass surgery. New England Journal of Medicine, 335(25), 1857-1864.

Rothenhäusler, H.-B., Ehrentraut, S., Stoll, C., Schelling, G., \& Kapfhammer, H.-P. (2001). The relationship between cognitive performance and employment and health status in long-term survivors of the acute respiratory distress syndrome: results of an exploratory study. General Hospital Psychiatry, 23(2), 90-96.

SAS, I. I. (2009). Cary, NC Patent No.: S. I. Inc.

Smith, A. (1982). Symbol Digits Modalities Test. Los Angeles: Western Psychological Services.

Wechsler, D. (1981). Manual of the Wechsler Adult Intelligence Scale - Revised. San Antonio: TX:The Psychological Corporation.

Wilson, R. S., Hebert, L. E., Scherr, P. A., Dong, X., Leurgens, S. E., \& Evans, D. A. (2012). Cognitive decline after hospitalization in a community population of older persons. Neurology, 78(13), 950-956 957p.

Wilson, R. S., Rajan, K. B., Barnes, L. L., Hebert, L. E., de Leon, C. F. M., \& Evans, D. A. (2013). Cognitive aging and rate of hospitalization in an urban population of older people. The Journals of Gerontology Series A: Biological Sciences and Medical Sciences, glt145. doi:10.1093/gerona/glt145

Volpato, S., Onder, G., Cavalieri, M., Guerra, G., Sioulis, F., Maraldi, C., . . Study, I. G. o. P. i. t. E. (2007). Characteristics of nondisabled older patients developing new disability associated with medical illnesses and hospitalization. J Gen Intern Med, 22(5), 668-674. 